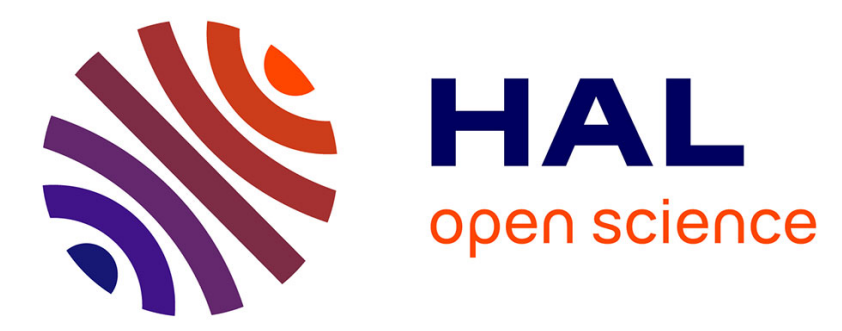

\title{
Glycemic control and the risk of mortality in elderly type 2 diabetic patients (ZODIAC-20)
}

Kornelis van Hateren, Gijs Landman, Nanne Kleefstra, Iefke Drion, Klaas Groenier, Sebastiaan Houweling, Henk Bilo

\section{- To cite this version:}

Kornelis van Hateren, Gijs Landman, Nanne Kleefstra, Iefke Drion, Klaas Groenier, et al.. Glycemic control and the risk of mortality in elderly type 2 diabetic patients (ZODIAC-20). International Journal of Clinical Practice, 2011, 65 (4), pp.415. 10.1111/j.1742-1241.2010.02596.x . hal-00623802

\section{HAL Id: hal-00623802 \\ https://hal.science/hal-00623802}

Submitted on 15 Sep 2011

HAL is a multi-disciplinary open access archive for the deposit and dissemination of scientific research documents, whether they are published or not. The documents may come from teaching and research institutions in France or abroad, or from public or private research centers.
L'archive ouverte pluridisciplinaire HAL, est destinée au dépôt et à la diffusion de documents scientifiques de niveau recherche, publiés ou non, émanant des établissements d'enseignement et de recherche français ou étrangers, des laboratoires publics ou privés. 


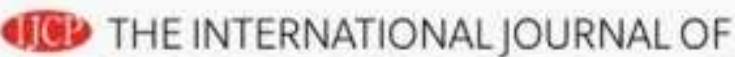 CLINICAL PRACTICE}

\section{Glycemic control and the risk of mortality in elderly type 2 diabetic patients (ZODIAC-20)}

\begin{tabular}{|c|c|}
\hline Journal: & International Journal of Clinical Practice \\
\hline Manuscript ID: & IJCP-08-10-0425.R2 \\
\hline Wiley - Manuscript type: & Short Report \\
\hline $\begin{array}{r}\text { Date Submitted by the } \\
\text { Author: }\end{array}$ & 09-Nov-2010 \\
\hline Complete List of Authors: & $\begin{array}{l}\text { van Hateren, Kornelis; Diabetes Centre, Isala Clinics } \\
\text { Landman, Gijs; Diabetes Centre, Isala Clinics; Isala Clinics, } \\
\text { Department of Internal Medicine } \\
\text { Kleefstra, Nanne; Diabetes Centre, Isala Clinics; Langerhans } \\
\text { Medical Research Group; University Medical Center Groningen, } \\
\text { Department of Internal Medicine } \\
\text { Drion, Iefke; Diabetes Centre, Isala Clinics } \\
\text { Groenier, Klaas; University Medical Center Groningen, Department } \\
\text { of General Practice } \\
\text { Houweling, Sebastiaan; Langerhans Medical Research Group; } \\
\text { General Practice Sleeuwijk } \\
\text { Bilo, Henk; Diabetes Centre, Isala Clinics; Isala Clinics, Department } \\
\text { of Internal Medicine; University Medical Center Groningen, } \\
\text { Department of Internal Medicine }\end{array}$ \\
\hline Specialty area: & \\
\hline
\end{tabular}

\section{SCHOLARONE" Manuscripts}


1

2

3

4

5

6

7

8

9

10

11

\section{Glycemic control and the risk of mortality in elderly type 2 diabetic patients (ZODIAC-} 20)

Running title: Glycemic control and mortality in old age

Kornelis J.J. van Hateren ${ }^{1}$, Gijs W.D. Landman ${ }^{1,2}$, Nanne Kleefstra ${ }^{1,3,4}$, lefke Drion ${ }^{1}$, Klaas H. Groenier $^{5}$, Sebastiaan T. Houweling ${ }^{3,5,6}$, Henk J.G. Bilo ${ }^{1,2,4}$

1. Diabetes Centre, Isala Clinics, Zwolle, The Netherlands; 2. Department of Internal Medicine, Isala Clinics, Zwolle, The Netherlands; 3. Langerhans Medical Research Group, The Netherlands; 4. Department of Internal Medicine, University Medical Center Groningen, Groningen, The Netherlands; 5. Department of General Practice, University Medical Center Groningen, Groningen, The Netherlands; 6. General practice Sleeuwijk, Sleeuwijk, The Netherlands.

Address for correspondence: Kornelis J.J. van Hateren, MD. Diabetes Centre, Isala Clinics. P.O. Box 10400, 8000 GK Zwolle, The Netherlands. Phone: +31-38-4242518, fax: +31-384243367. Email:k.j.j.van.hateren@isala.nl

Disclosure: we declare we have no (financial) conflict of interest.

Word count: main text 1673; abstract 250. 


\section{Abstract}

Aims Studies on macrovascular consequences of glucose control in elderly patients (>75 years) with type 2 diabetes mellitus (T2DM) are lacking. The present study aimed to investigate the relationship between $\mathrm{HbA}_{1 \mathrm{c}}$ and mortality in this specific population.

Methods Between 1998 and 1999, 374 primary care patients with T2DM aged older than 75 years participated in the ZODIAC study, a prospective observational study. Early 2009, data on mortality were collected. Updated means for annually measured $\mathrm{HbA}_{1 \mathrm{c}}$ values were calculated after a follow-up time of 10 years. Updated mean $\mathrm{HbA}_{1 \mathrm{c}}$ was used as a timedependent covariate in a Cox proportional hazard model. Main outcome measures were allcause and cardiovascular disease (CVD) mortality. Analyses were performed in strata according to diabetes duration $(<5,5-11$ and $\geq 11$ years $)$.

Results In the group with a diabetes duration $<5$ years, an increase of $1 \%$ in the updated mean $\mathrm{HbA}_{1 \mathrm{c}}$ level was associated with an increase in all-cause and CVD mortality risk of $51 \%(95 \% \mathrm{Cl} 17 \%-95 \%)$ and $72 \%(95 \% \mathrm{Cl} 19 \%-148 \%)$, respectively. Glycemic control was not related to mortality for patients with a diabetes duration $\geq 5$ years.

Conclusions Poor glycemic control is related to increased all-cause and CVD mortality in patients $>75$ years with T2DM of short duration ( $<5$ years).

Discussion Because of the observational study design, our results should be interpreted with caution. Nevertheless, they are suggestive that improving glycemic control may be beneficial in elderly patients with T2DM, especially in those with recently diagnosed T2DM. Randomised controlled trials are necessary to investigate whether this holds true.

Keywords Diabetes mellitus type 2; Aged; Mortality; Hemoglobin A, Glycosylated; Longitudinal studies. 


\title{
What's known?
}

The beneficial effects of improved glycemic control decrease with longer diabetes duration and with increasing age. However, there are no clinical data on the macrovascular and microvascular consequences of (intensive) glucose control in the very old (patients >75 years).

\begin{abstract}
What's new?
Higher levels of $\mathrm{HbA}_{1 \mathrm{c}}$ are related to increased all-cause and CVD mortality in diabetic patients aged older than 75 years, but only in those with diabetes of short duration $(<5$ years). Randomised controlled trials are necessary to investigate whether improving glycemic control in specific elderly diabetic populations, for example patients with newly diagnosed T2DM, may be beneficial.
\end{abstract}




\section{Introduction}

In a recent response to a meta-analysis of the Collaborators on Trials of Lowering Glucose (CONTROL) Group, the differences between patients with type 2 diabetes mellitus (T2DM) of short and long duration were emphasized $[1,2]$. Based on the heterogeneous results of four large randomised controlled trials, it seems that intensive glucose control is only beneficial in those with diabetes of short duration [3-6]. A meta-analysis, published in 2006, already showed that the beneficial effects of improved glycemic control decreased with longer diabetes duration and with increasing age [7]. Unfortunately, there are no clinical data on the macrovascular and microvascular consequences of (intensive) glucose control in adults older than 75 years. Although guidelines recommend to apply less stringent targets to frail older adults and those with limited life expectancy, the level of evidence of this advice is low and mainly based on expert opinion [8]. We aimed to explore the relationship between $\mathrm{HbA}_{1 \mathrm{c}}$ and (cardiovascular) mortality, and the role of diabetes duration in this relationship, in a prospectively designed cohort of elderly patients (>75 years) with T2DM. 
1

\section{Patients and methods}

\section{Study population}

This study is part of the ZODIAC (Zwolle Outpatient Diabetes project Integrating Available Care) study; the design and details of which have been presented elsewhere [9]. In this study, general practitioners are assisted by hospital-based diabetes specialist nurses in their care of patients with T2DM. At baseline, patients with a very short life expectancy (including patients with active cancer) or insufficient cognitive abilities were excluded $(\sim 5 \%)$. Four patients were excluded because of insufficient baseline data. Nearly $90 \%(n=1357)$ of the remaining patients agreed to participate. For the present study, we selected all patients aged older than 75 years $(n=374)$.

\section{Data collection}

Baseline data were collected in 1998 and 1999, and consisted of a full medical history including macrovascular complications, medication use, and tobacco consumption. Patients were considered to have macrovascular complications when they had a history of angina pectoris, myocardial infarction, percutaneous transluminal coronary angioplasty, coronary artery bypass grafting, stroke or transient ischaemic attack. Laboratory and physical assessment data, such as $\mathrm{HbA}_{1 \mathrm{c}}$, lipid profile, serum creatinine, the urinary albumin-tocreatinine ratio, blood pressure, weight, and height were collected annually. An updated mean of annually measured $\mathrm{HbA}_{1 \mathrm{c}}$ was calculated for each individual from baseline to the end of the follow-up period by averaging the baseline values with the mean annual values. For example, at one year the updated mean $\mathrm{HbA}_{1 \mathrm{c}}$ is the average of the baseline and one year values, and at three years it is the average of baseline, one year, two year and three year values. This technique is similar to the one used in the United Kingdom Prospective Diabetes Study (UKPDS) [10].

Clinical endpoints 
We examined two clinical endpoints in this study: all-cause and cardiovascular disease (CVD) mortality. Early 2009, the vital status and cause of death were retrieved from records maintained by the hospital and the general practitioners. The causes of death were coded according to The International Classification of Diseases, $9^{\text {th }}$ revision (ICD-9).

\section{Statistical analyses}

Continuous variables are presented as mean ( \pm standard deviation) for normally distributed values and as median (interquartile range) for non-normally distributed values. Normality was evaluated using Q-Q plots. Nominal variables are presented as the total number of patients (percentage). A Cox proportional hazard model was used to investigate the relationship between the updated mean $\mathrm{HbA}_{1 \mathrm{c}}$, as a time dependent covariate, and mortality with and without adjustment for selected confounders. We used two different models. In model 1, only age and gender were taken into account as possible confounders. In model 2, we adjusted for the following variables: age, gender, smoking (yes or no), BMI, duration of diabetes, serum creatinine, macrovascular complications (yes or no), albuminuria (yes or no), systolic blood pressure, total cholesterol-HDL ratio, and use of insulin (yes or no). Analyses were repeated in strata according to diabetes duration. The diabetes duration variable at baseline was categorised into tertiles: $<5(n=111), 5-11(n=139)$ and $\geq 11$ years $(n=124)$. In order to estimate the possible implications of higher $\mathrm{HbA}_{1 \mathrm{c}}$ levels on mortality, we calculated the population attributable risk percent (PAR\%) of $\mathrm{HbA}_{1 \mathrm{c}}$ levels $\geq 7 \%$ for all-cause and cardiovascular mortality [11]. In our analyses PAR\% can be interpreted as the percentage by which mortality rates could be reduced if all patients would have had $\mathrm{HbA}_{1 \mathrm{c}}$ levels $<7 \%$. The assumption of proportional hazards was checked by inspecting the Schoenfeld residual plots for the baseline predictor variables. All analyses were performed with SPSS version 15.0.1 (SPSS inc., Chicago, Illinois, USA).

Ethics statement 
The ZODIAC study and the informed consent procedure were approved by the local medical ethics committee. Informed consent was obtained from all patients. 


\section{Results}

Baseline characteristics of our study population are presented in table 1. Approximately one third of our study population was male. Median age (interquartile range) was 80 (78-83) years and median diabetes duration was 8 (4-13) years. Patients with a diabetes duration $\geq 11$ years (tertile 3 ) had lower mean BMI and were more often smokers compared to patients with shorter diabetes duration. The number of patients treated with only a diet was the highest in the group with a diabetes duration $<5$ years (tertile 1); also, use of insulin was the lowest in this group compared to patients with longer diabetes duration. After a follow-up time of 10 years, 304 out of 374 patients (81\%) had died, of whom 127 deaths (42\%) were attributable to cardiovascular causes.

\section{Analyses overall group}

In multivariate analyses (model 2), an increase of $1 \%$ in $\mathrm{HbA}_{1 \mathrm{c}}$ led to an increase in CVD mortality risk by $26 \%$ (95\% confidence interval (CI) 6-49\%). The unadjusted hazard ratio, and the age- and gender adjusted one, were not relevantly different. The relationship with allcause mortality was not significant in both models.

Analyses stratified according to diabetes duration (table 2)

In the group with a diabetes duration $<5$ years (tertile 1 ), the level of $\mathrm{HbA}_{1 \mathrm{c}}$ as a continuous variable was positively related to both all-cause and CVD mortality. In multivariate analyses, an increase of $1 \%$ in $\mathrm{HbA}_{1 \mathrm{c}}$ was associated with an increase in all-cause and CVD mortality risk of $51 \%(95 \% \mathrm{Cl} 17 \%-95 \%)$ and $72 \%(95 \% \mathrm{Cl} 19 \%-148 \%)$, respectively. All results for patients with a diabetes duration $\geq 5$ years were not significant.

Population attributable risk percent 

duration was 23\% (95\%Cl 2\%-36\%). For CVD mortality the PAR\% was 39\% $(95 \% \mathrm{Cl} 17 \%-$ $48 \%)$. Again, all results for patients with a diabetes duration $\geq 5$ years were not significant.

All analyses were repeated with only the baseline $\mathrm{HbA}_{1 \mathrm{c}}$ value as variable of interest (data not shown). Results did not relevantly change. The proportional hazards assumptions were met for all analyses. 


\section{Discussion}

Poor glycemic control is related to increased all-cause and CVD mortality in patients with T2DM aged over 75 years, but only in those with diabetes of short duration. In the lowest tertile (duration $<5$ years), the all-cause mortality risk was $51 \%$ higher for every $1 \%$ increase in $\mathrm{HbA}_{1 \mathrm{c}}$. For CVD mortality, the increase in mortality risk was even $72 \%$.

To our knowledge, the relationship between $\mathrm{HbA}_{10}$ and mortality in elderly patients with T2DM has not been described before. In previous observational and intervention studies elderly patients were either not included or subanalyses were not performed for this specific population. More recently, a large retrospective observational study showed that there seems to be a U-shaped association between $\mathrm{HbA}_{1 \mathrm{c}}$ and mortality [12]. Although an estimated $16 \%$ of the study population was aged over 75 years, no subanalyses were performed.

It is important to emphasize that the associations found between $\mathrm{HbA}_{1 c}$ and mortality in this study do not imply causality. Because of the observational nature of our study, we can only speculate about the underlying mechanisms. Firstly, poor glycemic control itself may indeed affect mortality risk in elderly patients with recently diagnosed diabetes. The heterogeneous results of four large randomised controlled trials in younger patients already suggested that intensive glucose control may only be beneficial with regard to mortality in those with diabetes of short duration [1,4-6,13]. Secondly, it may be possible that our results are influenced by confounders we did not adjust for. For example, the results for all-cause mortality may be confounded by co-morbidities such as cancer or infectious diseases. In order to reduce the impact of reverse causality we performed additional analyses for the overall group, in which we excluded the deaths in the first year of follow-up. This did not relevantly change, the results.

Besides its observational design, there are other reasons why our results should be interpreted with caution. Firstly, our study cohort is rather small and only comprises 374 elderly patients with T2DM. Since we also stratified our cohort into tertiles, the number in these tertiles are even smaller. Secondly, the heterogeneous health status of elderly patients 
1

2

3

4

5

6

7

8

9 makes it more difficult to identify the implications of our results for clinical practice. However, additional analyses revealed that for patients with a diabetes duration less than 5 years, the all-cause mortality rate could theoretically have been lowered by $23 \%$ if all patients had had $\mathrm{HbA} 1 \mathrm{c}$ levels $<7 \%$. An important strength of our study is its prospective design. Other strengths of our study are the high number of deaths after 10 years follow-up, the use of the updated mean method and the number of variables we adjusted for in our model.

Although our study is the first study linking higher levels of $\mathrm{HbA}_{1 \mathrm{c}}$ to increased mortality in elderly patients with recently diagnosed diabetes, we do not recommend aiming for intensive glycemic control for all subjects in this specific patient category. Intensive control may also lead to an increased risk of hypoglycemia causing possible adverse events such as fall accidents and fractures. Physicians caring for older patients should take comorbidity, frailty and estimated life expectancy into account when setting treatment goals for individual patients. Confirmation of our results in other cohorts would be interesting, because if confirmed, randomised controlled trials are necessary to investigate whether improving glycemic control in specific elderly diabetic populations, for example patients with newly diagnosed T2DM, may be beneficial.
Deleted: short

Deleted: be

Deleted: with

Deleted: when

Deleted: would have

Deleted: Notable

Deleted: the

Deleted: Randomised

Formatted: English (U.K.) 


\section{Author contributions}

Concept/design: KJJH, GWDL, NK, HJGB

Data collection: KJJH, GWDL, NK and ID.

Data analysis/interpretation: all authors.

Statistics: KJJH, GWDL and KHG.

Drafting article: $\mathrm{KJJH}$.

Critical revision of article: GWDL, NK, ID, KHG, STH and HJB.

Supervision: NK, STH and HJB.

Approval of article: all authors. 


\section{References}

1. Emanuele NV. Duration of diabetes, glucose control and cardiovascular risk. Diabetologia 2010; 53: 214-5.

2. Turnbull FM, Abraira C, Anderson RJ et al. Intensive glucose control and macrovascular outcomes in type 2 diabetes. Diabetologia 2009; 52: 2288-98.

3. Holman RR, Paul SK, Bethel MA, Matthews DR, Neil HAW. 10-year follow-up of intensive glucose control in type 2 diabetes. N Engl J Med 2008; 359: 1577-89.

4. The Action to Control Cardiovascular Risk in Diabetes Study Group. Effects of intensive glucose lowering in type 2 diabetes. N Engl J Med 2008; 358: 2545-59.

5. The ADVANCE Collaborative Group. Intensive blood glucose control and vascular outcomes in patients with type 2 diabetes. N Engl J Med 2008; 358: 2560-72.

6. Duckworth W, Abraira C, Moritz T et al. Glucose control and vascular complications in veterans with type 2 diabetes. N Eng J Med 2009; 360: 129-39.

7. Stettler C, Allemann S, Jüni P et al. Glycemic control and macrovascular disease in types 1 and 2 diabetes mellitus: Meta-analysis of randomized trials. Am Heart J 2006; 152: 2738.

8. American Diabetes Association. Standard of medical care in diabetes - 2010. Diabetes Care 2010; 33: S11-61.

9. Ubink-Veltmaat LJ, Bilo HJG, Groenier KH, Rischen RO, Meyboom-de Jong B. Shared care with task delegation to nurses for type 2 diabetes, a prospective observational study. Neth J Med 2005; 63: 103-10.

10. Adler AI, Stratton IM, Neil HAW et al. Association of systolic blood pressure with macrovascular and microvascular complications of type 2 diabetes (UKPDS 36): prospective observational study. BMJ 2000; 321: 412-9.

11. Natarajan S, Lipsitz SR, Rimm E. A simple method of determining confidence intervals for population attributable risk from complex surveys. Stat Med 2007; 26: 3229-39. 
12. Currie CJ, Peters JR, Tynan A et al. Survival as a function of $\mathrm{HbA1C}$ in people with type 2 diabetes: a retrospective study. Lancet 2010; 375: 481-9.

13. UK Prospective Diabetes Study (UKPDS) Group. Effect of intensive blood-glucose control with metformine on complications in overweight patients with type 2 diabetes (UKPDS 34). Lancet 1998; 352: 854-65. 


\section{Tables}

Table 1 Baseline characteristics.

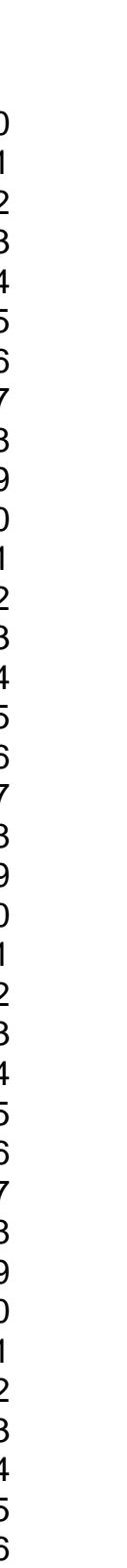




\section{Treatment T2DM}

$\begin{array}{lccccc}\text { - diet } & 40(10.7) & 19(17.1) & 13(9.4) & 8(6.5) & 0.025 \\ \text { - oral glucose lowering agents } & 265(70.9) & 85(76.6) & 102(73.4) & 78(62.9) & 0.050 \\ \text { - insulin } & 79(21.1) & 7(6.3) & 32(23.0) & 40(32.3) & <0.001 \\ \text { Receiving antihypertensive treatment } & 231(61.8) & 71(65.1) & 82(59.4) & 78(63.9) & 0.610 \\ \text { Receiving lipid lowering treatment } & 17(4.5) & 5(4.6) & 8(5.8) & 4(3.3) & 0.627\end{array}$

Data are means $( \pm \mathrm{SD})$, medians (interquartile range) or $n(\%)$. One-way ANOVA, Chi square, or Kruskal-Wallis test was used where appropriate to test for differences between groups. 
Table 2 Analyses stratified according to diabetes duration. Hazard ratios and the 95\% confidence intervals of $\mathrm{HbA}_{1 \mathrm{c}}$, for all-cause and cardiovascular disease (CVD) mortality.

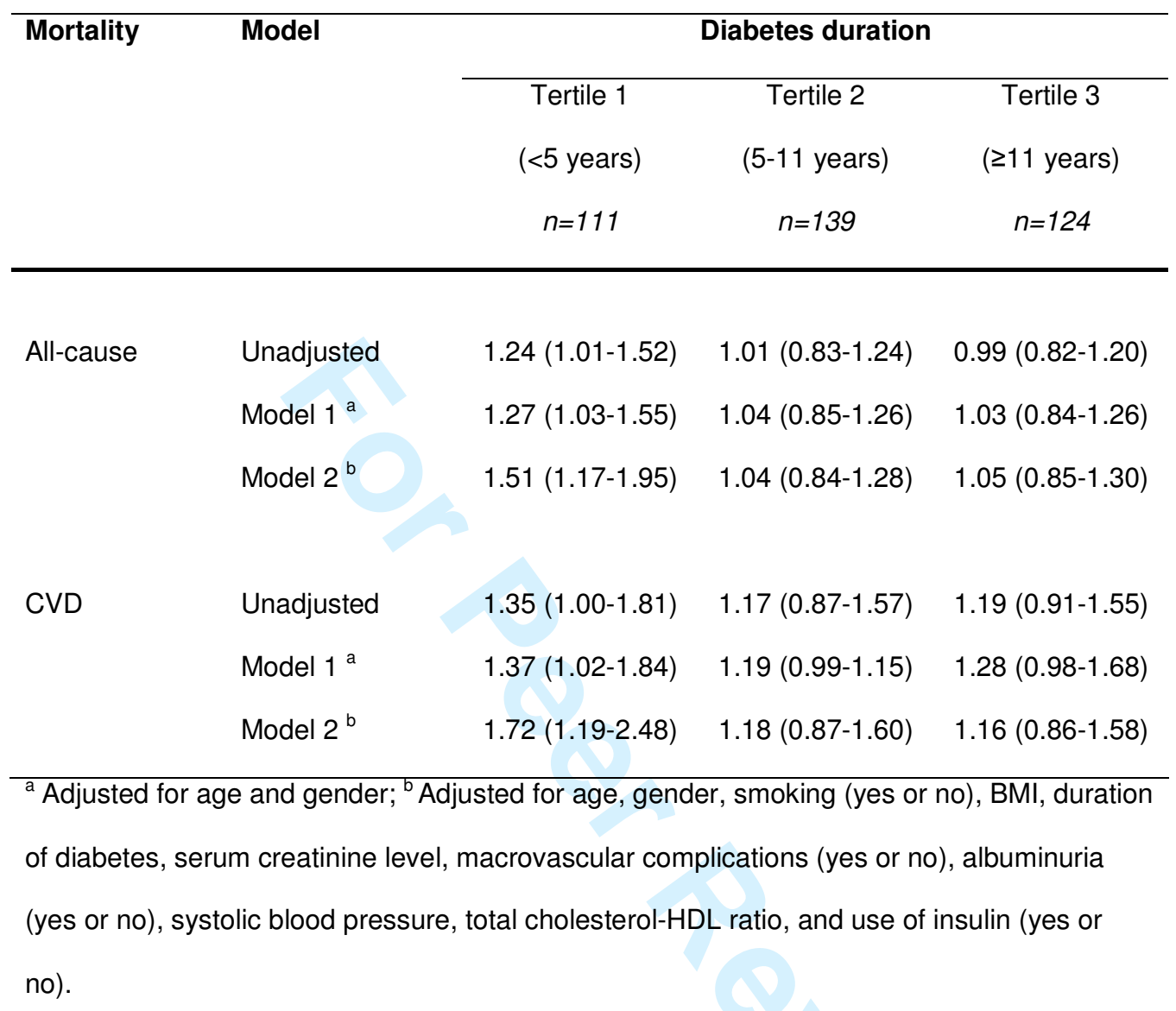

